\title{
Rethinking the knowledge bearing capacity of e-Business systems
}

\author{
Daniel F. Botha* \\ Department of Information Science, \\ Centre for Knowledge Dynamics and Decision Making, \\ University of Stellenbosch, Stellenbosch 7600, Republic of South Africa \\ dfbotha@sun.ac.za
}

Received October 2006

\begin{abstract}
Research was conducted in the area of sustainable knowledge extraction from e-business systems and technologies by exploring differentiating approaches from three notable authors seeking some common denominator to apply to a convergent approach in system conceptualization and design. It will be argued that most of e-business system upgrades and modification cost could be averted if the knowledge bearing capacity of proposed systems is realized and included as primary design parameters during the System Development Life Cycle. It will furthermore be argued that if this inclusive and integrative approach is followed it would lead to building a capacity to act that could be utilized for creating sustainable competitive advantage. Most e-Business system development is approached from an information processing and efficiency dimension, which more often than not exclude the knowledge utilization and effectiveness component as a design parameter. In most cases the primary focus is on information intensive functions, business process reengineering/automation and transaction processing whilst the use of information to discover knowledge assets and to innovate only comes into prominence after system implementation. This line of design thinking leads to the emergence of dominant designs which extend the scope for standardization whilst simultaneously limiting the scope for system variation. It will be proposed that re Boisot (1999), N-learning (neo-classical) thinking is normally dominant to Slearning (Schumpeterian) thinking during the e-business system design phase. The paper primarily draw on Max Boisot's Evolutionary Production Function and I-Space theoretical approach, Donald Marchand's Four Fundamental Principles of using Information to Create Business Value and Yogesh Malhotra's model on Balancing Design and Emergence for EBusiness Model Innovation. A new construct called the Knowledge Prospect Domain (KPD) will be identified and introduced as a common denominator between the models of the three authors on which to ground the approach to new thinking on e-business system design. To facilitate argumentation an attempt will be made to position the extant status of e-business systems in the I-Space, referring to what will be proposed as proprietary technologies and emergent technologies.
\end{abstract}

*To whom all correspondence should be addressed.

\section{Introduction}

During the conceptual, design and development phases of the System Development Life Cycle (SDLC) the knowledge bearing capacity of e-business systems such as SCM, ERP \& CRM applications are not always realized. After system implementation i.e. during the operational phase, attempts are made to draw on the knowledge capacity of these systems in order to discover knowledge that could add value to existing offerings and to create value for new offerings. This post facto and often ad hoc activity can incur considerable cost to companies through system application and system architecture modifications and up-grades.

Despite technological advancements in integration of processes, data processing, and information diffusion, ebusiness models have often been found lacking in adaptability, scalability and capacity planning - in all agility. More often than not technology implementation is done with little attention to organizational learning and latent knowledge discovery potential - in all knowledge bearing capacity.
The following quotations from noted authors in the field warrant retrospective sense making attention.

Malhotra (2002) states, that an increasingly greater need to integrate across extended inter-enterprise value chains and supply chains will demand better fusion of Enterprise Resource Planning (ERP) applications with Supply Chain Management (SCM) applications and Customer Relations Management (CRM) applications. Such integration of interenterprise information value chains will not be possible without supporting integration standards, computing processing power, data storage capacity, and network bandwidth capacity. CEOs and top executives of companies investing in next generation e-business platforms demand better justification for investments in e-business technology infrastructures and the articulation of expected business performance outcomes. But, a business environment characterized by rapid, radical and discontinuous change requires adaptive technologies and human creativity and sense making to work hand in hand.

Boisot (1999: 36) argues that standardization leads to performance improvement and these in turn leads to further standardization. Both taken together lead to complexity 
reduction and subsequently to production factor savings; the number of parts gets reduced, reliability increases, and a growing percentage of a products manufacture can be automated. At least as important, product attributes coevolve to constrain each other mutually, thus further extending the scope for standardization while simultaneously limiting scope for product variation. In this way dominant designs emerge and stabilize. Radical improvements or simplification become increasingly difficult to achieve once the downward shifts across transformation curves have occurred.

Donald Marchand (2002: 17-30) believes that senior managers struggling with the question on how to compete with information and IT to improve business performance face four challenges: to develop the right mindset; to understand how information creates business value; to use IT to build appropriate business competences; and to balance business flexibility and standardization. Most ebusiness systems already developed on scientific and engineering principles that serve a well defined set of processes and information flows are in complete cognitive dissonance with human social reasoning processes.

ERP is recognized as a necessary ingredient that many companies need in order to gain the efficiency, agility, and responsiveness required to succeed in today's dynamic business environment (O’Brien, 2004: 258). Accordingly eBusiness systems development must be both rapid and flexible with emphasis on branding, marketing and the user experience. These characteristics define a systems development life cycle (SDLC) quite distinct from that of traditional IT projects, thus organizations entering the realm of e-business must constantly re-examine their system development methodology (Weil \& Vitale, 2001). Over time, some of the current instability inherent in e-business system development processes is likely to subside as technologies stabilize and dominant designs emerge with inherent knowledge bearing capacity and agility.

The views expressed by these notable/extant authors, if taken collectively, could make pervasive arguments/reasons to rethink e-business system designs and developing strategies. Therefore the relevance of incorporating/creating knowledge bearing capacity in e-business systems during the design and development phase of the SDLC for systems such as SCM, ERP, and CRM as well as newer technologies appropriable for business use will be explored.

The hypothesis predicated in this paper is that future ebusiness infrastructures will demonstrate increasing convergence of proprietary technologies with emergent technologies which will impose design parametric challenges for exploiting knowledge bearing capacities in the knowledge prospecting domain (KPD).
The discussion will commence with an introduction of the models of Malhotra (2004), Marchand (2002) and Boisot (1999) on how they make sense of information to create knowledge for value in business systems. In these models the postulated Knowledge Prospect Domains (KPDs) for each of these authors will be identified. Secondly, the concept of Dominant Designs as postulated by Boisot will be applied to e-business systems. Subsequently, the position of current e-business systems as proprietary technologies and emergent technologies in the Boisot I-Space, will be argued. Lastly, a postulation/view on the exploitation of the knowledge bearing capacity of e-business systems will be proposed/presented.

\section{Defining knowledge prospect domains}

It is proposed that Knowledge Prospect Domains (KPDs) be those areas where knowledge, could be extracted by sense making practice, communities of practice, continual probing and intervention techniques (creative abrasion) integrating human and machine intelligence in a prospecting rather than mining mode; a domain where experimentation, scanning the edge of chaos, using creative-destructive-learning and system integration will lead to anticipated surprise; where prospecting for mineral wealth - knowledge discovery precedes mining for gold - knowledge utilization.

\section{Malhotra}

Yogesh Malhotra (2001a; 2001b; 2002; 2004) integrates the two worlds of e-business and knowledge discovery and sharing into a balanced model for business innovation as depicted in figure 1 . He emphasizes that developing an information-sharing technological infrastructure is an exercise in engineering design, whereas enabling use of that infrastructure for sharing high quality information and generating new knowledge - new reality (Marchand, 2002) is an exercise in emergence. While the former process is characterized by pre-determination, pre-specification and pre-programming for knowledge harvesting and exploitation, the latter process is characterized by institution/creation of organizational cultural infrastructure for community-based (stakeholder/value chain partners) interaction, considering core value propositions and thereby discovering new reality/knowledge (in a pre-thinking mode). This process is divergent and based on conflicting sense making by value-chain members operating in a loosely/relatively autonomous and self-organized, selfdirected, self-referenced and self-regulated modes.

Proposition 1: That the latter part of the Malhotra model, the area as shaded on the right-hand side of figure 1 , be qualified as a KPD. 


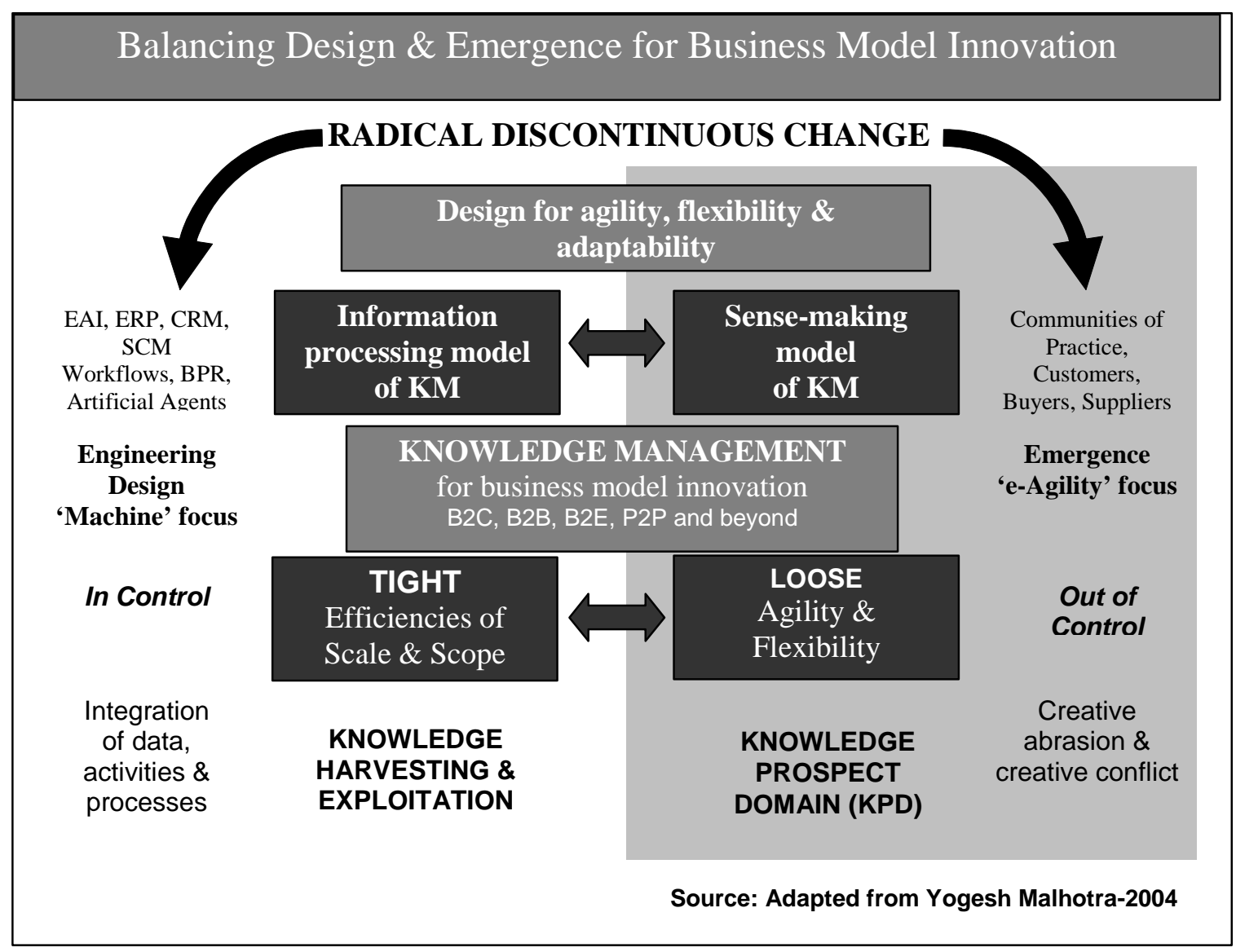

Figure 1 Knowledge Prospect Domain (KPD) identified in Malhotra Model

\section{MARCHAND}

Donald Marchand (2002:17-30) proposes four ways to use information to create business value. This he illustrates in what is now known as the Marchand Diamond diagram as depicted in Figure 2. The first domain is the risk management domain where data processing produces information for the continual improvement of the finance, accounting, auditing and controlling functions. These information intensive functions tend to be major consumers of IT and human resources.

The second domain of information use to create business value is the cost reduction domain. Here the focus is on using information as efficiently as possible to enhance/achieve the outputs required from business processes and transactions. This process view of information management is closely linked with the BPR and TQM movements of the 1990s. In both these domains information is mainly used to promote efficiency and could be collectively called the information-efficiency domain.

The third way proposed by Marchand is to use information to add value to products and services offered to customers by using information systems such as POS, data mining, and CRM systems from which new knowledge could be discovered to improve on these offerings. And, finally Marchand proposes the use of information to innovate - to invent new products, provide different services and using emergent technologies - to create new reality. This continuous discovery mode is about mobilizing people and collaborative work processes to share information and questioning existing paradigms of thinking. Both the latter two domains are about knowledge discovery to effect value creation; they could collectively be called the knowledgeeffectiveness domain.

Proposition 2: That by applying the definition of a knowledge prospect domain to the Marchand model the fourth domain, the domain of creating new reality, as shaded in Figure 2, be qualified as a KPD.

\section{Boisot}

In the seminal work of Max Boisot $(1995 ; 1999)$ the I-Space (Figure 3) is proposed as a conceptual framework within which the behaviour of the information flows that create knowledge assets, can be explored. Through the dimensions of codification (axis XY), abstraction (axis XZ) and diffusion (axis $\mathrm{XQ}$ ) the creation, utilization and sharing of knowledge within selected populations can be explained/understood. The key hypothesis advanced is that codification and abstraction are mutually reinforcing and that both acting together, greatly facilitate the diffusion of information through flows, causing stocks of knowledge assets to accumulate - knowledge capacity building. These flows of information for a given population can be represented by the Social Learning Cycle (SLC), as defined 
by Boisot and illustrated in Figure 3 (curve ABCDE). The SLC is decomposable into six phases (in sequence from A through $\mathrm{C}$ to $\mathrm{E}$ ), namely the scanning (identifying), problem-solving (codifying), abstraction (generalizing), diffusion (sharing), absorption (applying) and impacting (embedding) phases. In the I-Space Boisot furthermore proposes/argues for an ordered regime where entropy production is at its minimum (Emin) and a chaotic regime where maximum entropy production (Emax) is prevalent. These areas are also indicated in Figure 3. In between these two areas a complex regime exists.

Subsequently, Boisot (1999: 90-116) argues that section ABC of the SLC could be considered neo-classical learning or $N$-learning relating to the neoclassical perspective in economics. N-learning builds on an essentially linear view of the world; linearity that gives the world its stability and predictability - i.e., that makes it analytically tractable and computable. He labelled his second perspective on learning, S-learning or Schumpeterian learning in honour of Schumpeter and his 'gales of creative destruction', where new hypotheses are often destructive of old ones. Slearning, in contrast to N-learning, recognizes an overwhelmingly nonlinear world in which disequilibrating discontinuities originate. S-learning, denoted by CDE on the SLC, actively explores the creative potential of the lower regions - close to and inside the chaotic regime - of the ISpace and the nonlinear phenomena therein.

Proposition 3: That the characteristics of the last three phases of the SLC (delineated by C, D, and E), coupled with the definition of the chaotic regime, and with the concept of S-earning, qualifies this area of the I-Space (as shaded in Figure 3 - more so area DE), as a KPD.

Based on the three Propositions above it is suggested that sufficient evidence exist to single out KPDs as areas where Knowledge Mining/Extraction could be fruitfully pursued. That is, specific domains which should be formally appropriated in the conceptual and design phases of the ebusiness SDLC.

\section{The concept of dominant designs}

Boisot (1999: 19-40) proposes an Evolutionary Production Function for the Knowledge Society as opposed to the Neoclassical Production Function predicated for the Industrial Society by arguing for Data and Physical factors (energy, time and space) as production factors in place of Capital and Labour, the preferred factors of the traditional economic theorists. The Evolutionary Production Function, represented by successive isoquants (points of equal output per units of input) in Figure 4, illustrates how systems evolve and economize on its rate of consumption of physical factors by substituting physical factors for data factors. Successive acts of knowledge application (data processing, experience and skills - movement from 1-2, 3-4, 5-6, etc.) and knowledge creation (insights - movements from 2-3, 45 , 6-7, etc,) produces knowledge assets which economize on physical factors moving an organization's offering towards a dominant design. He argues that standardization leads to performance improvements, and these in turn lead to further standardization. Both taken together lead to complexity reduction and subsequently to factor savings; the number of parts gets reduced, reliability increases, and a growing percentage of a product's manufacture can be automated. At least as important, product attributes co-evolve to constrain each other mutually, thus further extending the scope for standardization while simultaneously limiting the scope for product variation. In this way a dominant design emerges and stabilizes (Boisot, 1999: 36). Following the emergence of a dominant design, innovation often becomes incremental.

\section{E-business systems}

By using the I-Space concept of Boisot it could be argued that for extensively integrated and standardized e-business systems, like ERP, SCM and CRM (example SAP), the information flows from these systems will be positioned to the left and top as indicated by the learning cycle LC1 in Figure 5(a). This is motivated by the following arguments: firstly, that these systems because of cost, time and space restrictions can only be afforded by a few large corporations - a limited population and therefore limited diffusion; secondly, that the operational knowledge extracted (by codification and abstraction) from these information flows is exclusively used to improve/enhance the business processes and transactions which predicates the information-efficiency domain; thirdly, that knowledge stocks are exploited from these resultant information flows through tight control, continual feedback and constant data-processing in an $\mathrm{N}$ learning mode and finally, all this takes place mainly internal to the organization - albeit across functional boundaries - where diffusion of information is restricted to a small population of systems and business analysts. Because of the dominant designs of these monolithic e-business systems the chaotic regime of the SLC and the S-learning approach are rarely exploited. It can be argued that the collective for these systems could be labelled Proprietary Technologies re Boisot (1999:59 \& 85).

Likewise it can be argued that for smaller/stand-alone ebusiness systems/technologies such as e-mail, instant messaging (IRC), mobile wireless services (SMS, texting, GPS), integrated speech and voice (VoIP, IVR, ASR, TSS), life caching (syndication, casting or blogging of text, photo, geocaching, audio and video) and others the learning cycle LC2, shown in Figure 5(b) will represent information flows at the top of and across the SLC stretching across organizational boundaries (external to the organization) in the value chain. They will represent a wider/larger population of disparate users using faster but shallower feedback loops, testing the boundaries of the chaotic regime in an S-learning mode but not appropriating it. They are not yet fully integrated into the conventional dominant ebusiness systems mainly because of interface incompatibility. These systems and technologies, constantly challenging e-business model design could be labelled Emergent Technologies (Boisot, 1999: 59 \& 85), presenting capacity for integration with Proprietary Technologies. 


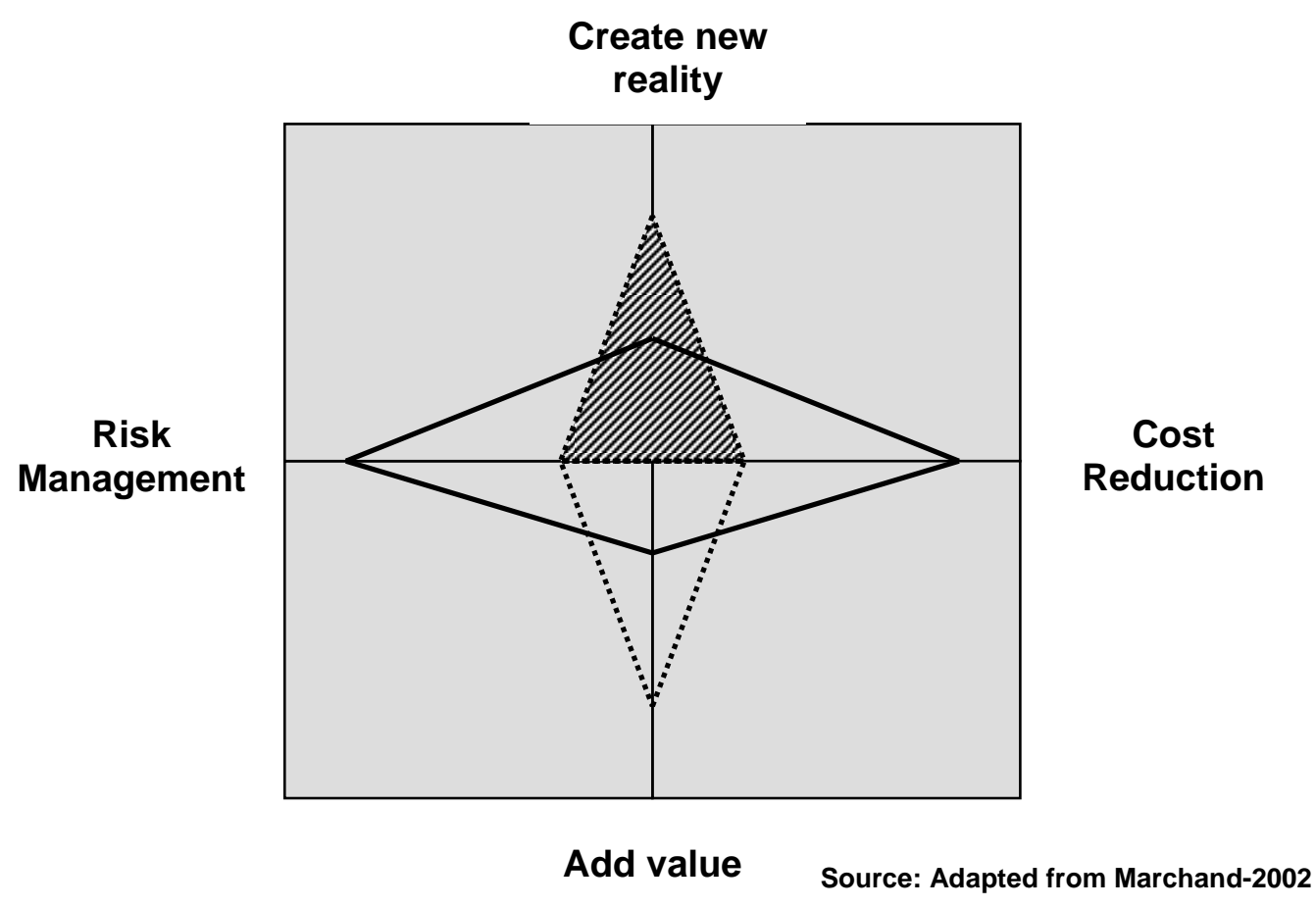

Figure 2: How information creates business value

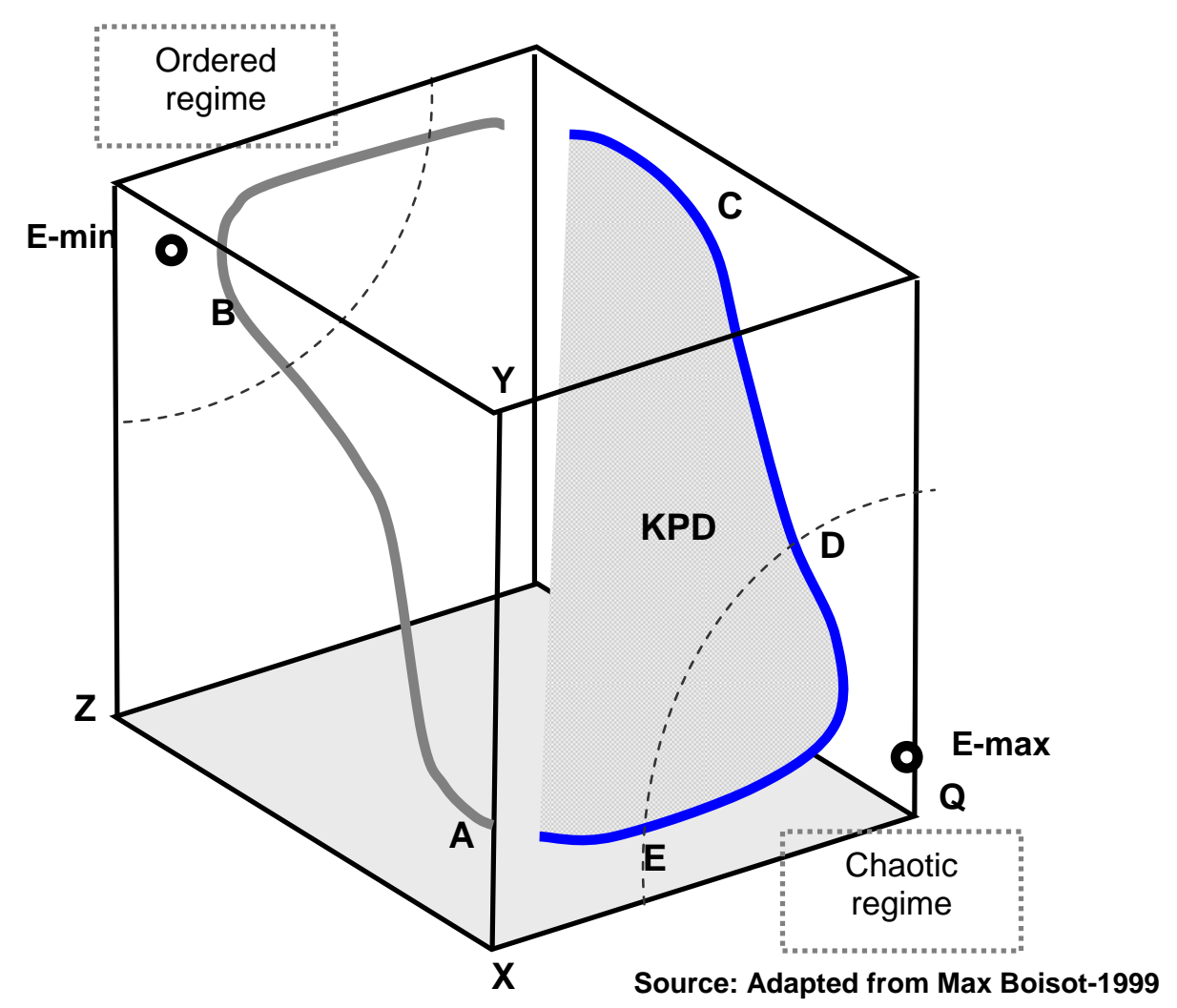

Figure 3: Knowledge Prospect Domain (KPD) in Boisot's I-Space 


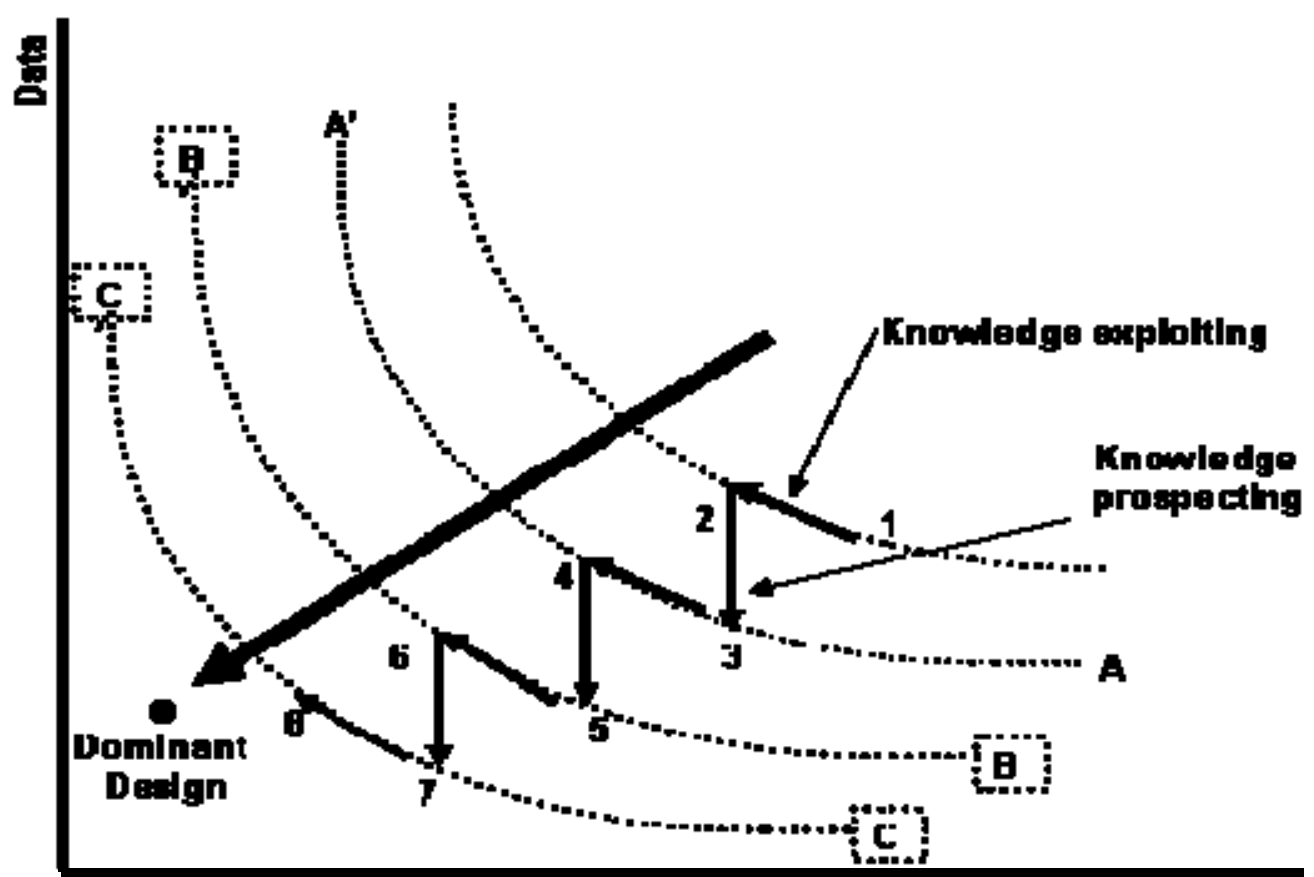

\section{An Evolutionery Production Function}

Phy:dral fanting:

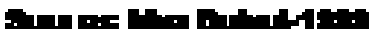

Figure 4: Boisot's evolutionary production function showing movement towards dominant design It is proposed that based on above argumentation, macro e-business systems like SCM, ERP, and CRM are moving towards dominant designs.

The proposition offered is that it can be argued that at present, e-business systems represented by LC1 are moving to the right of the SLC whilst those represented by LC2 are moving down the SLC as shown by the arrows in Figure 5. Furthermore, it is predicated that this will eventually lead to convergence/integration of e-business emergent technologies with proprietary technologies taking place in the KPD and influencing system conceptualization and design thinking. This integration will present new knowledge bearing capacity for which knowledge prospecting and extraction design parameters will have to be provided for in the Systems Development Life Cycle
(SDLC). According to Boisot (1999: 107) the critical knowledge/skill required to manage the systemic deployment of knowledge assets - in this case e-business systems - is systems integration. Sometimes it is achieved through modularization, where what is codified and abstracted is the relationship or interface between technologies which themselves remain 'black boxes'. Well structured interfaces allow a rapid diffusion of technologies without necessarily giving potential adopters access to them.

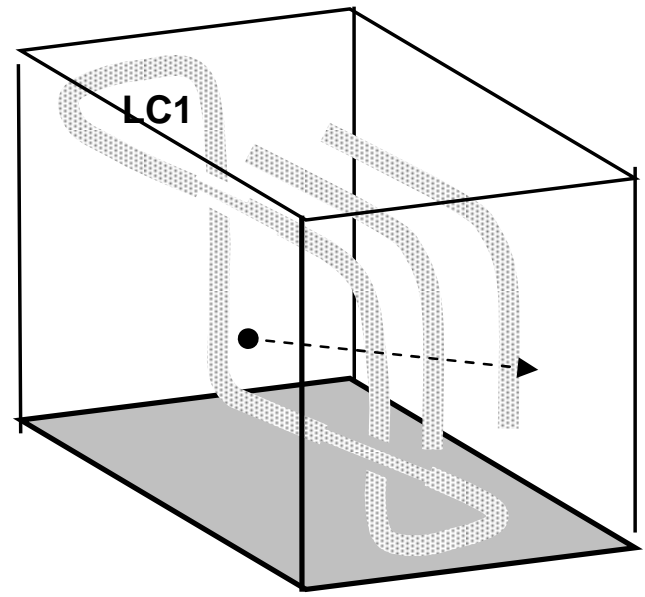

(a

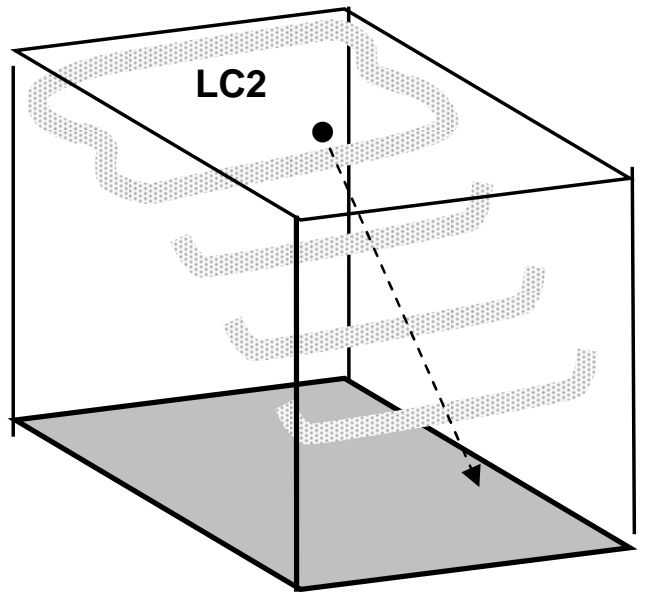

(b

Figure 5: Positioning e-business systems LCs in the Boisot I-Space 


\section{Conclusion}

From the recognized/realized models by Malhotra, Marchand and Boisot, dealing with knowledge exploitation in business organizations, an area proposed as the knowledge prospect domain (KPD) could be identified. This domain not normally mined for specific knowledge as in data mining was demarcated as having knowledge bearing capacity that could yield anticipated surprise knowledge assets for creating new reality. It can be realized as a domain where the prospector is not predisposed towards the type of knowledge to be discovered as in the case of the miner (the metaphor is: the miner mines for gold - the data mining of data warehouses - whereas the prospector seeks any mineral wealth - the data prospecting of knowledge warehouses). The domain was furthermore predicated as a domain where proprietary technologies and emergent technologies converge by integration, creating a new challenge in ebusiness system conceptualization and design; demanding new parameters for the SDLC in order to exploit the knowledge bearing capacity of the domain.

Further research is conducted at present to analyze and synthesize different SDLC models presented in the extant literature searching for goodness of fit with the concept of KPDs and the setting of a framework/guidelines for design parameters that will appropriate/exploit the knowledge bearing capacity of e-business systems - proprietary as well as emergent.

\section{References}

Boisot, M. 1999. Knowledge assets - securing competitive advantage in the information economy. London: Oxford University Press.

Boisot, M. 1995. Information space: a framework for learning in organizations, institutions and culture. London: Routledge.

Malhotra, Y. 2001a. 'Enabling next generation E-Business architectures: Balancing integration and flexibility for managing business transformation', Intel e-Strategy White Paper. [online] URL:

http://www.brint.com/papers/outsourc/

Malhotra, Y. 2001b. 'Expert systems for knowledge management: Crossing the chasm between information processing and sense making', Expert Systems With Applications, 20(1): 7-16.

Malhotra, Y. 2002. 'Enabling knowledge exchanges for ebusiness communities', Information Strategy: The Executives Journal, 18(3):26-31.

Malhotra, Y. 2004. 'Integrating knowledge management technologies in organizational business processes', Journal of Knowledge Management(Emerald). Special Issue on Knowledge Management and Technology, Q3.

Marchand, D. A. 2002. Creating business value with information. Chichester: J. Wiley \& Sons.
O'Brien, J. 2004. MIS: Managing IT in the business enterprise. $6^{\text {th }}$ Edition. Boston: McGraw-Hill/Irwin.

Weill, P. \& Vitale, M. 2001. Place to space - migrating to e-business models. Boston: Harvard Business School Press. 
